\title{
José Ribeiro Escobar e as orientações para o ensino de retângulo
}

\section{José Ribeiro Escobar and the guiderlines for rectangular education}

\section{José Ribeiro Escobar y las orientaciones para la enseñanza de rectángulo}

\author{
Joana Kelly Souza dos Santos \\ Universidade Federal de São Paulo, Campus Guarulhos \\ São Paulo, Brasil \\ E-mail: joanakelly.23@gmail.com \\ Orcid: 0000-0002-1805-554X \\ Luciane de Fatima Bertini \\ Universidade Federal de São Paulo, Campus Diadema \\ São Paulo, Brasil \\ E-mail: Ifbertini@gmail.com \\ Orcid: 0000-0003-0948-4745
}

\begin{abstract}
Resumo: Neste artigo foi traçado como objetivo examinar quais demandas passaram a ser colocadas aos professores que ensinavam geometria no curso primário paulista a partir das propostas de José Ribeiro Escobar para o ensino de retângulo. Foram analisadas as publicações desse autor nas Revista da Educação e Revista da Sociedade de Educação, ambas publicadas em São Paulo na década de 1920. A análise foi realizada a partir de uma recompilação (Valente, 2018) de orientações para o ensino de geometria, indicando que Escobar propôs ao professor paulista dois modos para ensinar retângulo. O primeiro o professor possuía o papel de condutor da lição, guiada pelo diálogo com seus alunos. O segundo versava sobre um ensino cultivado a partir da ação da criança, solicitada pelo professor. As orientações de Escobar $(1923,1924)$ sugeriam o estímulo da observação, memória, imaginação e raciocínio, iniciando com a comparação de materiais e formas geométricas e finalizando com a escrita dos conceitos como validação do conhecimento adquirido.
\end{abstract}

Palavras-chave: Ensino Primário. geometria. José Ribeiro Escobar. São Paulo 
Abstract: In this article the aim was to examine which demands was proposed to the teachers who taught geometry in the São Paulo primary school based on José Ribeiro Escobar proposals for teaching rectangle. The publications publishe by this author were analyzed in the Revista da Educação and Revista da Sociedade de Educação, both published in São Paulo in the 1920s. The analysis was carried out from a recompilation (Valente, 2018) of orientations for teaching geometry, indicating that Escobar proposed to the professor two proposals to teach rectangle: in the first the teacher had the role of conductor of the lesson, guided by dialogue with his students. The second was about a teaching from the action of the child, requested by the teacher. Escobar's guidelines $(1923,1924)$ suggested the stimulation of observation, memory, imagination and reasoning, starting with the comparison of materials and geometric forms and ending with the writing of concepts as validation of acquired knowledge.

Keywords: Primary Educacion. Geometry. José Ribeiro Escobar. São Paulo.

Resumen: En este artículo fue trazado como objetivo examinar qué demandas pasan a ser colocadas a los profesores que enseñaban geometría en el curso primario paulista a partir de las propuestas de José Ribeiro Escobar para la enseñanza de rectángulo. Se analizaron las publicaciones de este autor en la Revista de Educación y Revista de la Sociedad de Educación, ambas publicadas en São Paulo en la década de 1920.El análisis fue realizado a partir de una recompilación (Valente, 2018) de orientaciones para la enseñanza de geometría, indicando que Escobar propuso al profesor paulista dos propuestas para enseñar rectángulo: en la primera el profesor poseía el papel de conductor de la lección, guiada por el diálogo con sus alumnos. La segunda versaba sobre una enseñanza cultivada a partir de la acción del niño, solicitada por el profesor.Las orientaciones de Escobar $(1923,1924)$ sugerían el estímulo de la observación, memoria, imaginación y razonamiento, comenzando con la comparación de materiales y formas geométricas y finalizando con la escritura de los conceptos como validación del conocimiento adquirido.

Palabras- chave: Educación Primaria. geometría. José Ribeiro Escobar. São Paulo.

Recebido em $31 / 01 / 2021$

Aceito em

$01 / 04 / 2021$ 


\section{INTRODUÇÃO}

Este texto trata sobre a temática da formação de professores em uma perspectiva histórica, especificamente sobre professores que ensinavam geometria no curso primário paulista. O presente estudo pertence à uma pesquisa de doutoramento que tem por objetivo caracterizar o saber profissional do professor que ensinava geometria no curso primário durante o movimento pedagógico da Escola Nova.

O caso desta pesquisa vincula-se ao trabalho realizado pelo Grupo de Pesquisa da História da Educação Matemática (GHEMAT) que, a partir do desenvolvimento de um projeto maior , tem centralizado seus estudos no questionamento: que matemática como um saber profissional deve estar presente na formação de professores?

Tal questionamento leva-nos a investigar como são produzidos, sistematizados e institucionalizados os saberes profissionais do professor que ensina matemática. Para tanto, temos nos dedicado a mobilizar referentes teóricos-metodológicos de autores da Equipe de Pesquisa em História das Ciências da Educação (ERHISE) da Universidade de Genebra, na Suíça. Tais autores colocam em circulação o interesse em estudar os saberes, aqueles tipos de conhecimentos que passam por um processo de objetivação, institucionalização e sistematização que possibilite a fundamentação neles mesmos, sem ser necessária uma explicação terceira de quem o produziu (Vincent, Lahire \& Thin, 2001).

Diante do cenário desses estudos, Valente, Bertini e Morais (2017), ao apropriarem-se dos estudos de Hofstetter e Schneuwly (2017) apresentam os saberes profissionais como uma articulação entre os saberes que são vindos dos diferentes campos disciplinares e considerados importantes para a formação, portanto constituem o objeto de trabalho do professor e, diante de seu ofício, passa a relacionar-se com a cultura escolar - saberes a ensinar - e os saberes próprios para o exercício da profissão, àquelas ferramentas necessárias para o trabalho do professor - saberes para ensinar (Hofstetter, Schneuwly, 2017). 


\section{Universidade Federal da Grande Dourados}

Considerando os saberes profissionais como a articulação entre os saberes a ensinar e saberes para ensinar, Valente, Bertini e Morais (2017) apontam que em cada tempo histórico são sedimentados saberes específicos para a formação de professores e para o ensino de matemática, levando em conta que ao longo do tempo a matemática passa por transformações e essas mudanças indicam a produção de novos saberes profissionais. Então, ao longo das décadas saberes distintos dos já consagrados disciplinarmente foram sedimentados, de modo a caracterizar o saber profissional do professor que ensina matemática, pensando, em particular, no ofício dessa profissão.

Tratando em específico desta pesquisa, que conforme já elencado está vinculada a um projeto guarda-chuva que considera a matemática na formação de professores e no ensino, leva-se em consideração, em particular, a circulação de saberes específicos para o professor que ensinava geometria no curso primário paulista.

Conforme já apresentado anteriormente, a questão central do projeto guardachuva é ampla, então, de modo a contribuir com os estudos que vem sendo desenvolvidos, neste texto apresentamos o exame de dois artigos de autoria de José Ribeiro Escobar que tratam especificamente sobre o ensino de retângulos, todos publicados em exemplares de revistas pedagógicas paulistas. A saber, Uma aula sobre rectangulos, publicado no número 02 da Revista da Educação em 1923; Area do rectangulo, publicado no número 09 da revista da Sociedade de Educação em 1920.

Com o uso dessas fontes nosso objetivo é examinar quais demandas passam a ser colocadas aos professores que ensinavam geometria no curso primário paulista a partir das propostas de José Ribeiro Escobar. Assim, esta pesquisa busca responder à questão: quais elementos de geometria podem ser recompilados nas orientações colocadas aos professores para o ensino de retângulos discutidos por José Ribeiro Escobar em revistas pedagógicas paulistas da década de 1920? 


\section{O ENSINO SOBRE RETÂNGULO NO CURSO PRIMÁRIO PAULISTA POR JOSÉ RIBEIRO ESCOBAR}

Autor de diversos artigos de revistas pedagógicas de todo o Brasil , José Ribeiro Escobar foi professor na Lente de Matemática no período de 1921 a 1927. Álgebra e aritmética no ano de 1931, na Escola Normal. Escobar escreveu também livros que discutiam sobre o ensino do curso primário (Campos, 2019). Considerando a trajetória desse autor, é possível identificar sua contribuição para o professor que ensinava matemática à época, por consequência, na influência de produções de saberes matemáticos.

De acordo com Campos (2019), Escobar era um autor de livros e manuais destinados ao ensino de um modo geral, trazendo orientações e direcionamento para professores de todas as matérias, mas, em especial para o tratamento do ensino de matemática que, de acordo com o autor, como aponta Campos (2019, p. 23), defendia para o "aprendizado matemático que é necessário a cultura da atenção, observação, memória, imaginação e raciocínio. Ele recomenda que se recorra à origem histórica para entendimento das modificações que ocorreram nos conteúdos matemáticos", buscaremos, então, de que maneira ele aborda o ensino de retângulo e se esses passos persistem com importância para o autor.

Antes de tratarmos sobre as análises das fontes, cabe apontar que a opção de considerar o uso de revistas pedagógicas deve-se ao fato delas constituírem

[...] uma instância privilegiada para a apreensão dos modos de funcionamento do campo educacional enquanto fazem circular informações sobre o trabalho pedagógico e o aperfeiçoamento das práticas docentes, o ensino específico das disciplinas, a organização dos sistemas, as reivindicações da categoria do magistério e outros temas que emergem do espaço profissional (Catani, 1996, p. 117).

Elas são tomadas como meio importante de divulgação de ideias pedagógicas por auxiliarem "na compreensão da distância que fica entre os textos e as práticas escolares, entre os discursos que propõem a formação ideal e as realidades 
resistentes às injunções institucionais" (Catani \& Sousa, 2001, p. 244), pelo fato de fazer circular

[...] informações sobre o trabalho docente, a organização dos sistemas de ensino, as lutas da categoria profissional do magistério, bem como os debates e polêmicas que incidem sobre aspectos dos saberes ou das práticas pedagógicas, tornam as mesmas uma instância privilegiada para a investigação dos modos de funcionamento do campo educacional (Catani, 1996, p.116).

Ao considerarmos que as revistas pedagógicas eram tomadas como um importante espaço de divulgação de informações referentes ao exercício da docência a época de nosso estudo, partimos da consideração que "[...] a leitura e a análise das revistas, dos manuais etc. buscaria capturar métodos, didáticas, objetivo pedagógicas que poderiam ser lidos como integrantes do movimento de constituição de saberes para ensinar e saberes a ensinar" (Valente et al., 2017, p.232).

Desde o início deste texto vem sendo discutido sobre saberes, cabe agora, então, antes de iniciarmos nossas análises, tratar sobre o que temos entendido como saberes e de que maneira ele se constitui. Tomando como fio condutor a obra $\mathrm{O}$ que é história do conhecimento? de autoria de Burke (2016), Valente (2018) apresenta uma análise em que considera uma distinção entre as categorias de conhecimento e saber. Enquanto a primeira está mais relacionada à subjetividade, as experiências de um indivíduo, localizado em um determinado tempo, lugar e comunidade, o segundo, saber, passa por um processo de sistematização e objetivação, desprende-se do sujeito que o produziu para fazer-se circular. E é sobre esta segunda categoria que consideramos nesta pesquisa: um estudo dos saberes, mais especificamente, a análise de saberes da geometria para o ensino de retângulos.

Conforme já apontado, dadas as categorias de saberes a ensinar, saberes para ensinar e saber profissional consideradas anteriormente, Valente, Bertini e Morais (2017) afirmam que em cada período do ensino e da formação de professores, surgem saberes específicos. Tais saberes, por sua vez, são distintos dos consagrados disciplinarmente na matemática enquanto ciência, passaram por processos de sistematização, objetivação institucionalização. 


\section{Universidade Federal da Grande Dourados}

Ao nos referirmos a uma discussão sobre saberes que são diferentes dos consagrados disciplinarmente, partimos da premissa de que há uma matemática vinda do cotidiano, daquele que sabe calcular, mas não precisou de conceitos formais para isso, além dela, uma matemática vinda da escola, ligada às demandas da docência e uma matemática enquanto objeto científico (Moreira \& David, 2003). Essa discussão nos leva a considerar que há uma matemática que exige uma certa abstração, a dos cursos superiores, mas, ela também convoca do professor do curso primário uma linguagem cabível àqueles anos escolares, numa forma que seja perceptível para aquele grupo.

Nesse sentido, apropriando-se dos estudos da equipe de ERHISE, Valente, Bertini e Morais (2017) elaboram as categorias teóricas de matemática a ensinar $\neg-$ considerada como a matemática que o professor deverá ensinar, não somente os conteúdos, mas a constituição que cada tempo pede - e a matemática para ensinar relacionada a ferramenta do trabalho docente, é aquilo que o professor precisa saber para ensinar matemática, mobilizada a partir da matemática a ensinar. A partir de uma apropriação dessas categorias elencadas por Valente, Bertini e Morais (2017), neste texto busca-se discutir sobre as orientações para ensinar retângulo no curso primário.

Para discutir sobre essas orientações para o ensino do curso primário, considerando o processo de transformar informação em saberes, tomamos a categoria de recompilação de experiências docentes por Valente (2018) que afirma que, ao nos referirmos sobre o saber profissional do professor que ensina matemática, precisamos "considerar etapas como recompilação de experiências docentes, análise comparativa dos conhecimentos dos docentes, sistematização e uso dos conhecimentos como saberes" (Valente, 2018, p. 380).

Essa recompilação de experiências docentes, que aqui consideramos como recompilação de orientações para o ensino de conceitos da geometria, conforme o que aqui temos entendido, está relacionada ao conjunto de informações que constam em diversas fontes e apresenta um apanhado de conhecimentos dispersos num dado tempo histórico (Valente, 2018), a primeira etapa na busca do "processo de 
transformar informações em conhecimento por meio de práticas como descrição, quantificação, classificação e verificação" (Burke, 2016, p. 89).

Assim, considerando o objetivo de examinar quais demandas passam a ser colocadas aos professores que ensinavam no curso primário a partir das propostas de José Ribeiro Escobar em se tratando do ensino de geometria, foram recompiladas as orientações para o ensino sobre retângulo no curso primário analisados em dois artigos de revistas pedagógicas do Estado de São Paulo, produzidos por Escobar.

A opção por tratar sobre as orientações para o ensino de retângulo ocorreu por, de acordo com Frizzarini (2014), este ser um dos conteúdos presentes no rol de recomendações para o ensino de geometria presente em documentos oficiais da década de 1920 no Estado de São Paulo. Cabe também destacar que

[...] a publicação de José Escobar nesse periódico não foi isenta de intervenções políticas e particulares. Ele não só foi membro da Sociedade de Educação, como também assumiu cargos nas atividades promovidas por essa instituição. Atuou como Primeiro Secretário de 11 de julho de 1923 a 11 de dezembro de 1924. Fez parte de uma comissão junto com Sampaio Dória e Léo Vaz, a qual foi criada pela própria instituição a fim de determinar quais livros seriam publicados. (Oliveira, 2015, p. 547)

Cabe então apontar de que maneira este autor direcionava o ensino à época. No primeiro artigo identificado, datado no ano de 1923, Escobar (1923) apresenta um estudo sobre o aprendizado indutivo, para o autor, considerado como um meio de "explicar o Mundo e o Homem" (Escobar, 1923, p. 163). Em uma nota de aula sobre retângulos destinada a professores do curso primário o autor sugere aos mesmos que considerem três graus no conhecimento de seus alunos, três etapas ascendentes. A observação é a primeira delas, quando parte desta etapa e considera-se as definições como segundo grau de conhecimento e o último deles é representado pela síntese de tudo o que é apreendido levando em conta a relação das leis, termos e princípios.

A marcha que o espirito segue para adquirir conhecimentos: Os seres ou cousas não podem ser conhecidos em si, em substancia, mas têm propriedades que os tornam capazes de produzir phenomenos (como: números, extensão, movimento, 


\section{Universidade Federal da Grande Dourados}

peso, luz, som, combustão, ou respiração, revolução, vingança); os phenomenos impressionam os sentidos, e por meio das sensações produzem as imagens; as imagens por meio da percepção se transformam em ideias; as ideias por meio das relações formam os juízos; os juízos, pelo raciocínio, as illações; as illações, por meio dos processos (observação, comparação, etc) dão o empirismo, conhecimento dos phenomenos ou factos; o empirismo, por meio do methodo, se torna sciencia, conhecimento das leis dos phenomenos; a sciencia, por meio das theorias passa a ser philosophia conhecimento dos princípios (Escobar, 1923, p. 165).

Ao considerar uma marcha de ensino que parte do que Escobar (1923) chama de aprendizado indutivo, esse autor, buscando atingir o alcance do conhecimento, acredita que a aprendizagem é realizada seguindo os passos destacados no excerto anterior. Para ele as noções dos conceitos são recebidas pelos alunos pelos olhos e ouvidos e a partir daí realiza-se um caminho que sai "pelos nervos optico e auditivo ao cerebro" (Escobar, 1923, p. 163).

Para o alcance de todos esses passos elencados, Escobar (1923) propõe que "a indução é o melhor methodo para adquirir conhecimentos e a dedução para verificar a verdade das leis induzidas" (Escobar, 1923, p. 167). Então, o professor é orientado a explorar os processos de observação, experimentação, comparação, generalização seguindo os passos, conforme figura 1. 


\section{METHODOS PROCESSOS MOMENTOS}

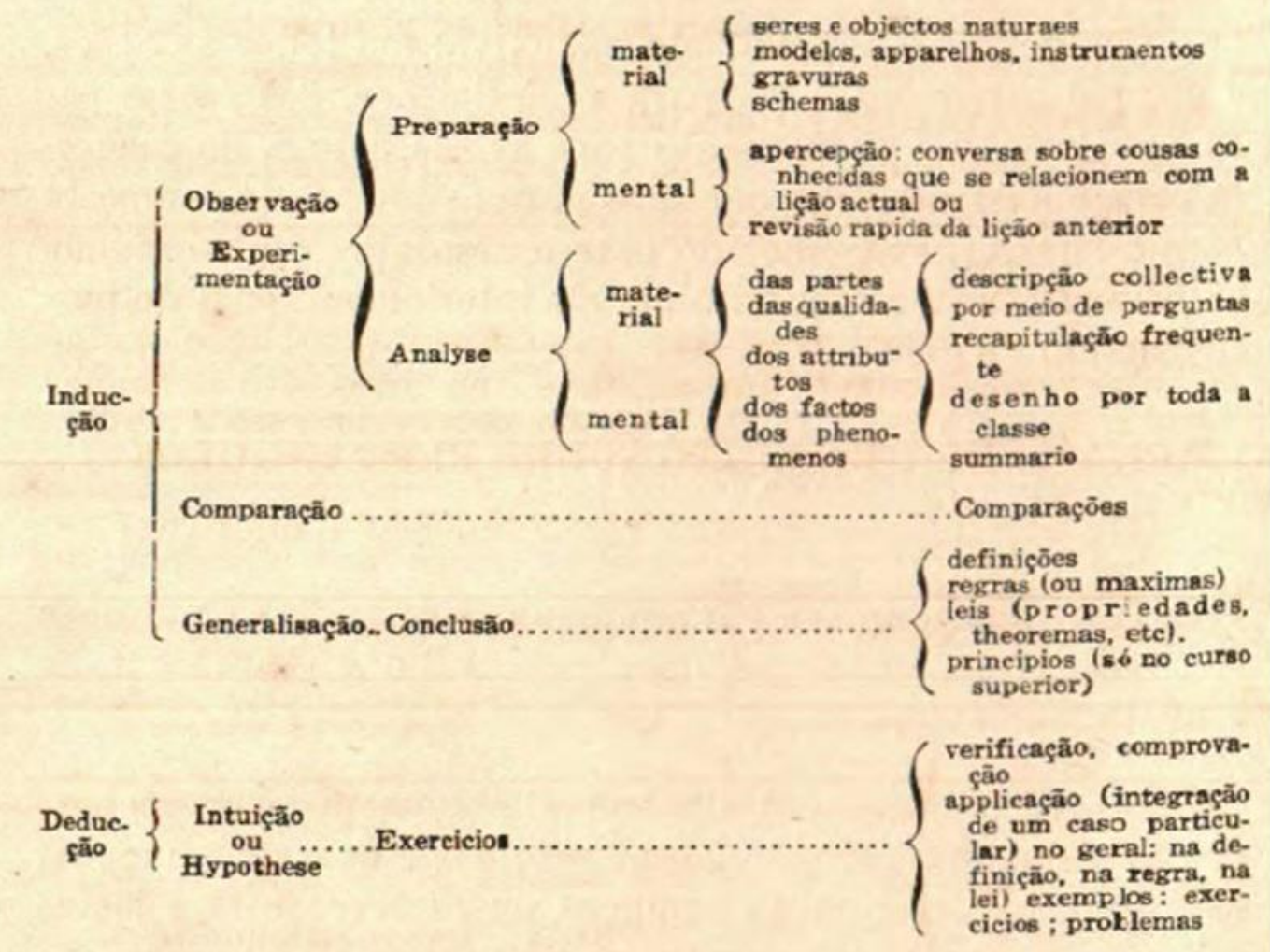

Figura 1- Como deve ser realizado o ensino no curso primário

Fonte: Escobar, 1923, p. 170

Para trabalhar com a temática dos retângulos seguindo esse método proposto, Escobar (1923) orientou aos professores que fossem considerados critérios de aprendizado educativo para que desenvolvesse nas crianças o sentido tátil, muscular por meio de corpos geométricos, levando-as a observar, analisar e abstrair por meio da superfície, linhas, ângulos, a cultivar a linguagem e generalizar, devendo a definição ser realizada pelo aluno, aplicado os passos da figura 1 no ensino do conceito de retângulo, conforme figura 2. 


\section{Universidade Federal da Grande Dourados}

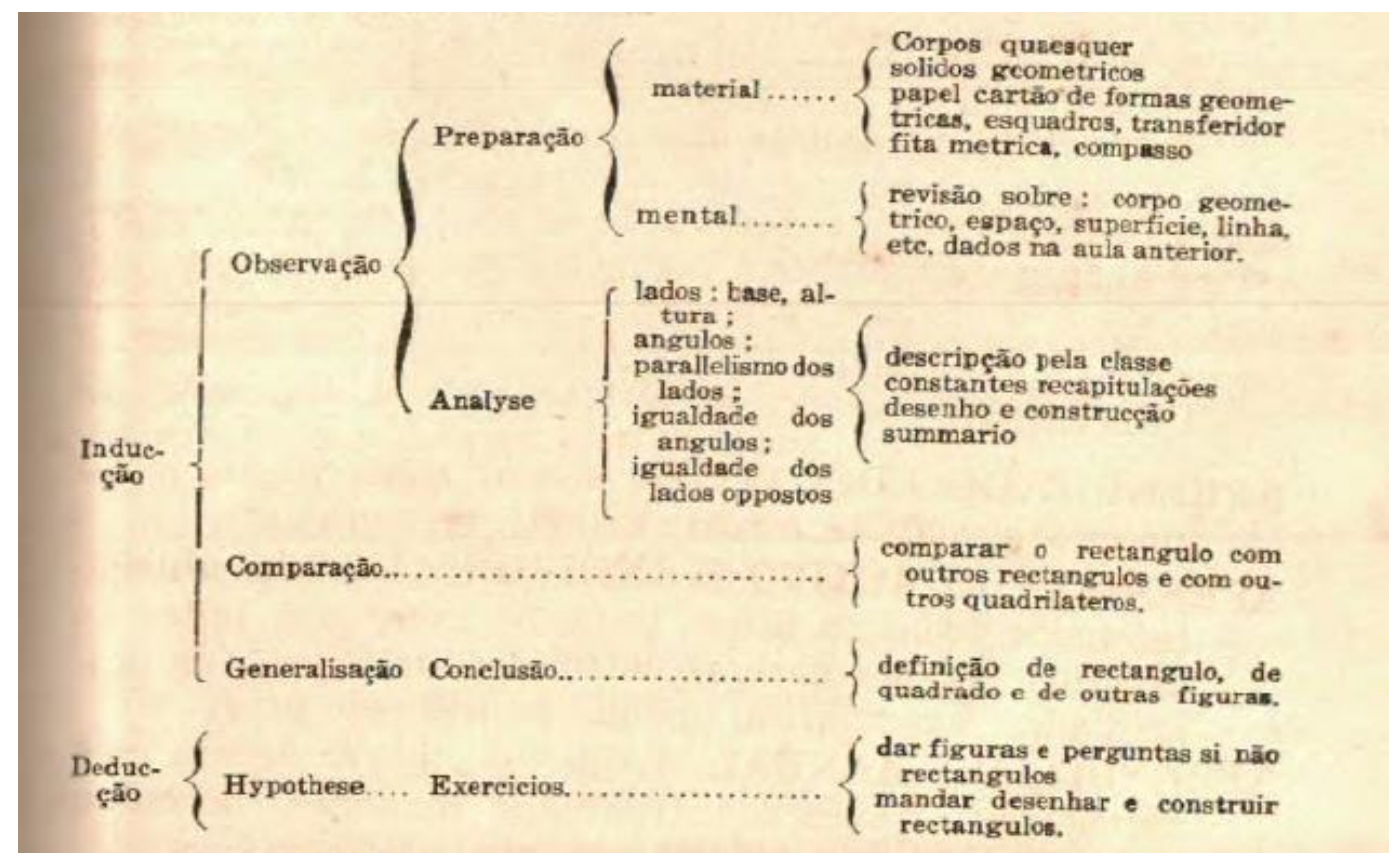

Figura 2 - Método para ensinar o conceito de retângulo por Escobar

Fonte: Escobar, 1923, p.171

Esses direcionamentos dados por Escobar (1923) para o ensino de retângulo estão associados a forma que a geometria era considerada a época "como a parte experimental da matemática, concluindo que é uma ciência de observação e de experiência e que, portanto, deveria ser ensinada pela observação e experiência" (Lima \& Lando, 2020, p. 161).

A sugestão de Escobar (1923) era a de que as aulas fossem realizadas a partir de diálogos entre o professor e os alunos, seguindo os passos apresentados na figura 2. Inicia-se pela observação a partir da preparação material, com o professor apresentando um prisma e explicando brevemente suas características, mostrando que que se trata de um corpo geométrico e daí instigando as crianças a identificarem corpos geométricos na sala.

Ao que parece, Escobar (1923) seguiu as indicações ao professor considerando o que Campos (2019) chama como cultura da atenção, observação, memória, 


\section{Universidade Federal da Grande Dourados}

imaginação e raciocínio para o autor, dado que o estímulo central estava em levar as crianças a observar e imaginar objetos, um ensino pelas formas.

Tal orientação para o ensino do curso primário era um modo recorrente do trabalho com a geometria que buscava apresentar ao professor "um tipo de conhecimento para ensinar, nela evidencia-se como os conteúdos estudados por ele na sua formação deveriam ser ensinados em outra perspectiva: adaptados e transformados seriam mobilizados com uma finalidade mais ampla de desenvolvimento da criança" (Oliveira \& Lima, 2020, p. 143).

Isso não significa que existe uma maneira correta ou errada de se ensinar retângulo no curso primário, mas que quando Escobar (1923) sugeria um ensino pautado na observação e imaginação, quando seguiu para a etapa da preparação mental e orientou que nesta fase o professor começasse a trabalhar com superfície, linhas, ângulos do retângulo, um processo de conduzir a adoção de um ensino das figuras geométricas do todo para as partes, ensinando retângulos por meio de concepções intuitivas, que priorizam a associação, percepção, memória e raciocínio nas atividades, ele estava realizando uma abordagem em que considerava o que para ele era importante ser feito diante do cenário educacional paulista.

Apesar de ter realizado uma proposta de diálogo entre professor e aluno, em que o primeiro ficava à espera das respostas das crianças para avançar nas observações de objetos disponíveis em sala, Escobar (1923) não apresentava esses questionamentos de modo linear e repetitivo, a interação entre professor e aluno deveria ter um caráter de análise que atendesse a fixação dos conceitos com a comparação de materiais, para o alcance do conhecimento a partir da fala e depois da escrita como modo de fixação de aprendizagem, conforme o trecho que segue.

[...] Mostrem na carteira, os lugares em que ella se separa do espaço. Vamos dar um nome a esta separação; chama-se SUPERFICIE. Quem me repete essa palavra?

Jandyra: - Superficie.

Prof. - Passem a mão nas superfícies da carteira, da nessa, do livro, da parede, etc. Escrevam essa palavra nos seus papeis. (Mostrando um parallelipipedo á 


\section{Universidade Federal da Grande Dourados}

classe). Quem é capaz de mostrar o lugar em que termina esta superficie? [...] (Escobar, 1923, p. 172)

Do que fora apresentado anteriormente consideramos que Escobar (1923) orientou aos professores que realizassem o estímulo da observação dos alunos mediante a linguagem oral e tomasse a escrita como modo final de alcance do conhecimento. Fato também observado por Oliveira (2015) ao estudar as orientações de José Ribeiro Escobar para o ensino de saberes aritméticos.

Oliveira (2015, p. 548) observou que Escobar, trabalhando o ensino de aritmética com centro nos problemas, conduziu uma recomendação aos professores para que atendesse à uma ordem "metodológica sobre a qual o ensino tende a seguir: primeiro, dar nomes aos números representados pelos objetos concretos (os tornos); em seguida, escrever símbolos, isto é, algarismos, desses números”. Talvez essa seja uma característica que o autor dos artigos nas revistas pedagógicas atendia à época, seguir a demanda de ensino ligado às coisas, a materialidade dos objetos por meio dos sentidos da criança, adotando, possivelmente uma orientação de ensino próxima de ideais do método intuitivo .

As orientações de Escobar (1923) para o ensino de retângulos seguem nessa característica de diálogo entre professor e aluno, iniciando pela observação, pelo toque e encerrando com a escrita. Quando passa a ser considerado o tópico pelo autor denominado de Observação: analyse um outro elemento passa a compor o quadro de questionamentos realizados pelo professor: as medições.

O uso de instrumentos como régua e atividades que são desenvolvidas do espaço para o plano ganharam espaço nas orientações para o ensino de retângulo. Ao que parece, para Escobar (1923) fez-se necessário um professor que adotasse o ensino com a observação e o uso de objetos sendo os principais mediadores das capacidades de raciocínio das crianças, não de maneira superficial, mas fixando a ideia da exatidão das medidas de figuras geométricas.

Foi identificado que a orientação de Escobar (1923) dizia respeito a um professor com papel de mediador para estimular a criança ao alcance do conhecimento 


\section{Universidade Federal da Grande Dourados}

mediante o uso do diálogo, tudo passava por ele, os materiais pertenciam a mão do professor, o diálogo era promovido por questões por ele realizadas, porém não era destinado ao educador realizar as definições esperadas, ele estimulava seus alunos a chegarem na teoria e realizava as correções quando necessário.

Para Escobar (1923) havia a necessidade de deixar firmado na criança concepções como o que são formas e figuras geométricas e de que modo elas apareciam no cotidiano, em especial, comparando com materiais que possuíssem formas semelhantes ao retângulo, tema da aula. Identificamos então uma geometria nas orientações para o ensino de retângulo que possui a finalidade de aplicação para a vida, regida a partir dos sentidos da criança e centro no diálogo conduzido pelo professor. Além disso, existia também um critério de validação na produção de saberes concernentes a aula deste autor, para Escobar (1923), apesar de apresentar elementos que considera a geometria como uma ciência das formas, regida pela materialidade, era importante que o professor realizasse a validação do conhecimento através da escrita.

O segundo artigo de Escobar é datado de 1924 e segue uma linha de orientações semelhante a que fora apresentada anteriormente. $O$ autor continua dividindo a condução da aula em preparação material e preparação mental, mas agora aparecem novos procedimentos: generalização pelos alunos; indução da regra pelos alunos; aprendizado retentivo; maior abstração: fórmula; aplicações: atividades manuais; educação dos sentidos; problemas (gráfico, escrito, mental, imaginado pelos alunos, da vida real) e construção: slojd .

Nessa orientação era recomendado que os alunos tivessem em mãos folhas de papel de cálculo, lápis, régua e esquadro, sólidos geométricos como paralelepípedos e cilindros de papeis construídos previamente pela própria criança a partir de atividades de cartonagem. A partir desses materiais que a aula deveria ser conduzida.

Já desde o preparo do material é possível considerar uma nova característica na orientação de Escobar (1924): o aluno passou a ter em mãos materiais (como alguns tipos de sólidos geométricos) que antes fora identificado apenas como posse do 
professor. A sugestão era de que a aula fosse iniciada a partir de um problema (figura 3) com a finalidade de ter despertado o interesse do aluno e promovido um ensino associado ao cotidiano, próximo da realidade da criança.

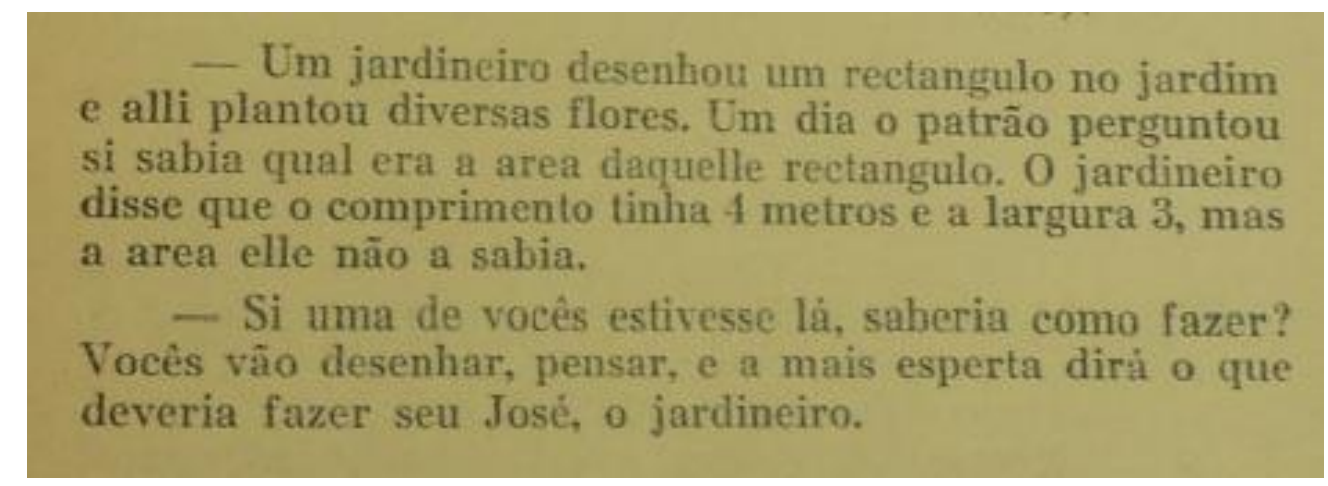

Figura 3 - Ensino de retângulos por meio de problemas

Fonte: Escobar, 1924, p. 255

O problema apresentado na figura 3 pertence ao espaço no artigo chamado por Escobar (1924) de historieta para despertar o interesse; aprendizado associativo e interessante. Nessa etapa o professor deveria conduzir o ensino de modo que instigasse as crianças o trabalho manual a partir de desenhos de retângulos, com medidas exatas feitas com apoio dos instrumentos disponíveis para elas, como a régua, e então realizassem uma observação para comparar o que foi feito pelos alunos com essa atividade anterior.

Dessa forma, nota-se então uma diferenciação na condução do alcance do conhecimento orientada por Escobar (1924) com relação ao artigo analisado anteriormente, passa-se de uma aula guiada por meio do diálogo entre professor e aluno, para um ensino cultivado a partir da ação da criança solicitada pelo professor.

A ação exercida pelos alunos não foi realizada de qualquer maneira. Escobar (1924) orientou que os professores conduzissem seus alunos a realizar desenhos de medidas exatas, como por exemplo: "façam "todas", cada uma no seu papel, um rectangulo de quatro centimetro de base e tres $\mathrm{cm}$ de altura; marquem os centimetros; por esses pontos de divisão tracem rectas" (Escobar, 1924, p. 255). 


\section{Universidade Federal da Grande Dourados}

Não havia uma proposta de diálogo nas orientações, mas tinha questionamentos relacionados às construções realizadas pelas crianças, relacionando com outros conteúdos matemáticos, como a multiplicação "(Analyse) - Como acharam a área do rectangulo? - Não ha um modo de achar o numero de $\mathrm{cm}$ ? Ou de $\mathrm{dm}^{2}$ sem contal-os todos? Que operação se faz? (Multiplicação)" (Escobar, 1924, p. 256).

Nesse momento passa-se a considerar não somente uma educação pelos sentidos da criança, despertando o interesse por meio da observação dos materiais, mas a própria adoção dos trabalhos manuais e a importância da materialidade dos conceitos na aula deveria seguir de modo que a exatidão das medidas das figuras geométricas fosse priorizada, indicando que a fixação das definições estavam presentes em todos os momentos da aula.

Como finalização, Escobar (1924) orientou que fossem trabalhados vários tipos de problemas, inicialmente um problema gráfico, em que o aluno tinha que construir retângulos, então o que ele considerava por problema gráfico, ao que tudo indica, era um exercício de desenho, trabalhando a capacidade motora da criança. A aula seguiu com problema escrito, em que a criança deveria resolver em seu material as questões sugeridas pelo professor e também com questões as quais o aluno deveria responder com uso do cálculo mental e depois elaborar problemas, a partir de modelos já realizados anteriormente, encerrando esta etapa com problemas da vida real, que nada mais era que questões relacionadas a alguma situação, como "[...] tenho um terreno no Jardim America de 30 x 45, no valor de 54 contos: quanto custa o metro quadrado?" (Escobar, 1924, p. 258).

Tal exercício indica que Escobar (1924) priorizava a adoção de conceitos geométricos a partir da construção dos sentidos da criança, mas que não o fazia somente por meio da imaginação e observação. A observação, mas também a ação e o raciocínio eram importantes meios de se atingir o objetivo de alcançar o conhecimento, então era necessário que o professor organizasse sua aula priorizando o estímulo da criança, mas tendo a linguagem escrita e a construção das definições a partir das medidas como forma de fixação dos conceitos. 


\section{Universidade Federal da Grande Dourados}

\section{CONSIDERAÇÕES}

Neste texto foram analisados artigos de revistas pedagógicas paulistas com 0 objetivo de examinar quais demandas passam a ser colocadas aos professores que ensinavam geometria no curso primário a partir das propostas de José Ribeiro Escobar para o ensino de retângulo. A pesquisa teve como condução a questão: quais elementos de geometria podem ser recompilados nas orientações colocadas aos professores para o ensino de retângulos discutidos por José Ribeiro Escobar em revistas pedagógicas paulistas da década de $1920 ?$

Ao analisar duas propostas para ensinar retângulos, a primeira que ocupava-se de iniciar com um sólido geométrico e, depois, trabalhar com suas partes, linhas, ângulos, até chegar no retângulo e suas propriedades, exploradas através de questionamentos entre professor e aluno e a segunda com uma adoção diferente, o aluno passando a ter mais ação na aula através do exercício de desenho, trabalhos manuais e medida de objetos, sendo o foco da aula não somente nos sentidos da criança, mas na construção do conceito já desde o início da atividade, foi identificado que Escobar apresentou a adoção de elementos da geometria em seus artigos que ocupava ações que ganham espaço de saber, um saber a ser ensinado em se tratando do estudo de retângulos.

Ao que parece, as orientações realizadas por Escobar $(1923,1924)$ nos deixam a reflexão de que a geometria ganha passos que nos convidam a pensar em status de um saber a partir do uso de medidas, desenhos, trabalhos manuais e educação dos sentidos da criança, mas com sua validação principal no processo de escrita. Para esse autor era a partir desses elementos que a necessidade de que os alunos se apossassem das nomenclaturas, definições e medidas exatas das figuras geométricas que indicam a geometria para o ensino sobre retângulos.

Tais elementos confirmam a consideração feita por Campos (2019) de que Escobar orientava ao professor que ensinava matemática no curso primário a adoção do ensino que estivesse relacionado ao estímulo da observação, memória, 


\section{Universidade Federal da Grande Dourados}

imaginação e raciocínio. Em cada uma dessas etapas Escobar $(1923,1924)$ sugeria que o conteúdo fosse transformado de modo que partisse do que era mais fácil e visual para a criança - a observação e comparação de materiais com formato semelhante ao retângulo - até a chegada ao alcance do conhecimento - validação por meio da escrita e medições exatas através do uso de instrumentos.

Escobar colocou em circulações orientações que instigassem o professor a considerar ações dos alunos como tato e observação apontando para uma progressão de ensino, que vai do desconhecido ao generalizado, as conduções por ele colocadas aos professores do curso primário indicava que este deveria preocupar-se não somente com conceitos de modo abstratos, mas com elementos instigados pela imaginação da própria criança, pela construção de diálogos estabelecidos entre professor e aluno, pela associação com aspectos cotidianos. O professor, conduzindo a adoção do conteúdo do todo para as suas partes, da geometria espacial para a plana, construía as relações entre conceitos trabalhados em sala para a formação das crianças enquanto cidadãs de uma sociedade.

\section{AGRADECIMENTOS}

O presente trabalho foi realizado com apoio da Coordenação de Aperfeiçoamento de Pessoal de Nível Superior (CAPES).

\section{REFERÊNCIAS}

Bertini, L. F.; Morais, R. S.; Valente, W. R. (2017). A Matemática a ensinar e a Matemática para ensinar: novos estudos sobre a formação de professores. São Paulo: Editora Livraria da Física.

Burke, P. (2016). O que é história do conhecimento? 1. ed. São Paulo: Editora Unesp. 
Campos, A. M. A. (2019). As Intervenções De José Ribeiro Escobar No Ensino Da Matemática Em São Paulo Nas Primeiras Décadas Do Século Xx. HISTEMAT Revista de História da Educação Matemática, v. 5, n. 1, p. 20-33.

Catani, D. B. (1996). A Imprensa Pedagógica Educacional: As Revistas de Ensino e o estudo do Campo Educacional. Educação e Filosofia. Uberlândia, MG, v. 10, n. 20, p. 115-130, Jul.-Dez.

Catani, D. B., Sousa, C. P. (2001). A geração de instrumentos de pesquisa em História da Educação: estudos sobre revistas de ensino. In: VIDAL, D.G.; HILSDORF, M.L.S. Brasil 500 anos: tópicas em História da Educação. São Paulo: EDUSP.

Escobar, J. R. Area do rectangulo. IN: Revista da Sociedade de Educação, 1924, n.9, vol.III dez. SP. Disponível em: https://repositorio.ufsc.br/handle/123456789/131179.

Escobar, J. R. (1923). Uma aula sobre rectangulos. IN: Revista da Educação, 1923, n.2, jun. SP. Disponível em: https://repositorio.ufsc.br/handle/123456789/160194.

Ferreira, J. S. (2019). Os fins do ensino de matemática na proposta de josé ribeiro escobar para o programa de aritmética e álgebra da escola normal de são paulo, 1926. HISTEMAT - Revista de História da Educação Matemática, v. 5, n. 1, p. 3448.

Frizzarini, C. R. B (2014). Do Ensino Intuitivo para a Escola Ativa: os saberes geométricos nos programas do curso primário paulista, 1890-1950. Dissertação 
(mestrado) - Universidade Federal de São Paulo, Programa de Pós-Graduação em Educação e Saúde na Infância e na Adolescência.

Frizzarini, C. R. B (2018). Saberes matemáticos na matéria Trabalhos Manuais: processos de escolarização do fazer, São Paulo e Rio de Janeiro (1890-1960). Tese (doutorado) - Universidade Federal de São Paulo, Programa de PósGraduação em Educação e Saúde na Infância e na Adolescência.

Lima, E. B., Lando, J. C. (2020). À mão livre ou com régua e compasso: saberes geométricos para o ensino primário em tempos da vaga pedagógica intuitiva. In: Oliveira, M. C. A.; Pinto, N. B.; Valente, W. R. A Aritmética, a Geometria e o Desenho. A matemática nos primeiros anos escolares. São Paulo: Livraria da Física.

Lima, E. B., Lando, J. C. (2020). A observação e o fazer para ensinar Geometria, Desenho e Trabalhos Manuais: a formação de professores e a pedagogia escolanovista. In: Oliveira, M. C. A.; Pinto, N. B.; Valente, W. R. A Aritmética, a Geometria e o Desenho. A matemática nos primeiros anos escolares. São Paulo: Livraria da Física.

Moreira, P. C.; David, M. M. M. S. (2003). Matemática escolar, matemática científica, saber docente e formação de professores. Zetetike, v.11, n.19, pp. 57-80.

Oliveira, M. A. (2015). As recomendações de José Ribeiro Escobar para o ensino de saberes aritméticos no curso primário. In: Anais do XII Seminário Temático 
Saberes Elementares Matemáticos do Ensino Primário (1890-1970). Disponível em: http://www2.td.utfpr.edu.br/seminario tematico/ANAIS/46 MARCUS.pdf

Santos, J. K. S., Leme da Silva, M. C. (2019). Orientações para ensinar geometria na revista de ensino de Alagoas (1927-1930), VIDYA Revista Eletronica, v. 39, n. 2.

Souza, A. F. (2016). O MÉTODO INTUITIVO NOS MANUAIS ESCOLARES E NAS REVISTAS PEDAGÓGICAS: orientações para utilização de problemas nas aulas de aritmética. In: Anais do XIV Seminário Temático Saberes Elementares Matemáticos do Ensino Primário (1890-1970): sobre o que tratam os manuais escolares?

Disponível

em: https://xivseminariotematico.paginas.ufsc.br/files/2016/05/SOUZA T2 vf.pdf.

Valente, W. R. (2018). Processos de investigação histórica da constituição do saber profissional do professor que ensina matemática. Revista Acta Scientiae, v. 20, p. 377-385.

Valente, W. R. Bertini, L. F.; Pinto, N. B.; Morais, R. S. (2017). A Matemática na Formação de Professores e no Ensino: processos e dinâmicas de produção de um saber profissional, 1890-1990. Projeto de Pesquisa. São Paulo: FAPESP, 2017. Disponível em: http://bv.fapesp.br/pt/auxilios/98879/a-matematica-naformacao-de-professores-e-no-ensino-processos-e-dinamicas-de-producao-deum-saber-p/?q=17/15751-2 
Vincent, G.; Lahire, B.; Thin, D. (2001). Sobre a história e a teoria da forma escolar. Educação em Revista, Belo Horizonte, n. 33, jun.

\section{CONTRIBUIÇÕES dOS AutORES}

$1^{\text {a }}$ autor: conceitualização; curadoria de dados; análise formal; investigação; metodologia; administração do projeto; supervisão; visualização; redação - rascunho original; redação - revisão e edição.

$2^{\circ}$ autor: administração do projeto; supervisão; visualização; redação - rascunho original; redação - revisão e edição. 